\title{
The role of deep brain stimulation in Parkinson's disease: an overview and update on new developments
}

\author{
John Y Fang \\ Christopher Tolleson \\ Department of Neurology, Vanderbilt \\ University Medical Center, Nashville, \\ TN, USA
}

This article was published in the following Dove Press journal:

Neuropsychiatric Disease and Treatment

7 March 2017

Number of times this article has been viewed
Abstract: Parkinson's disease (PD) is a progressive neurodegenerative disorder characterized by the loss of neuronal dopamine production in the brain. Oral therapies primarily augment the dopaminergic pathway. As the disease progresses, more continuous delivery of therapy is commonly needed. Deep brain stimulation (DBS) has become an effective therapy option for several different neurologic and psychiatric conditions, including PD. It currently has US Food and Drug Administration approval for PD and essential tremor, as well as a humanitarian device exception for dystonia and obsessive-compulsive disorder. For PD treatment, it is currently approved specifically for those patients suffering from complications of pharmacotherapy, including motor fluctuations or dyskinesias, and a disease process of at least 4 years of duration. Studies have demonstrated superiority of DBS and medical management compared to medical management alone in selected PD patients. Optimal patient selection criteria, choice of target, and programming methods for PD and the other indications for DBS are important topics that continue to be explored and remain works in progress. In addition, new hardware options, such as different types of leads, and different software options have recently become available, increasing the potential for greater efficacy and/or reduced side effects. This review gives an overview of therapeutic management in PD, specifically highlighting DBS and some of the recent changes with surgical therapy.

Keywords: Parkinson's disease, deep brain stimulation, functional neurosurgery

\section{Background}

Since the initial description of the "shaking palsy" in 1817 by James Parkinson, Parkinson's disease (PD), which bears his name, has presented patients and clinicians with significant treatment challenges due to the debilitating neurologic complications related to the disease. ${ }^{1}$ The motor symptoms (asymmetric resting tremor, bradykinesia, rigidity, and postural instability) have been the signature, or cardinal, features of PD, for which most treatments have been directed and have achieved the most success. Although these motor findings do not all develop simultaneously, patients must have bradykinesia plus one other feature at presentation to meet diagnostic criteria. ${ }^{2,3}$ In the mid-20th century, anticholinergic medications became the first medications to be consistently beneficial for these symptoms, although to a somewhat limited degree beyond tremor. It was not until the late 1960s that levodopa therapy became established as the mainstay of symptom management and drastically altered PD therapy, given its pronounced benefit. ${ }^{4}$ Over the years, several new formulations of levodopa and combinations with other medications have become available. In addition, synthetic dopamine receptor agonists have also become an important standard therapy for many PD patients. 
Limitations of PD pharmacotherapy include the need for frequent dosing to avoid the return of symptoms (eg, "wearing off" or other types of motor fluctuations) and also the occurrence of dyskinesias, generally choreatic movements that occur with advancing disease. ${ }^{5}$ Neuropsychiatric and autonomic side complications can also limit therapy in many patients either as a byproduct of medication usage or secondary to pure disease progression..$^{6-8}$

Surgical therapies have consequently become attractive options for some patients with advancing disease because of more continuous uniform delivery of therapy, which diminishes off time and lessens dyskinesia severity. Greater efficacy can be potentially attained with these types of surgeries without the need for increasing oral medication dosing, which may result in fewer side effects, particularly reduced dyskinesias. ${ }^{9-14}$ Deep brain stimulation (DBS) is currently the most popular surgical intervention in the USA for movement disorders. Other widely utilized invasive or surgical interventions for PD include the gel-based carbidopa-levodopa enteral suspension, which is infused by an external pump through a jejunostomy tube, and the subcutaneous apomorphine pump (not US Food and Drug Administration [FDA] approved). ${ }^{15-18}$ While intriguing, these two invasive therapies will not be discussed in this review.

DBS involves implanting programmable multicontact electrodes in specific anatomic targets "deep" within the brain. These electrodes are connected by a tunneled extension wire that connects to a neurostimulator typically placed subcutaneously below the clavicle. DBS has proven to be safe and efficacious in several studies. ${ }^{9-14}$ Still, DBS, like any surgery, is not without risks and its own side effects. These effects may include worse cognition, impaired verbal fluency, depression, cerebral hemorrhage, stroke, and infection among others. ${ }^{14,19-23}$ In addition, unlike many other types of surgeries, DBS requires long-term maintenance for proper functioning, including both software programming adjustments and hardware battery replacements.

The "best" treatment for the symptoms of PD has remained highly individualized over the years, despite the addition of medical and surgical therapies. This review will focus on an overview of medical and DBS management in $\mathrm{PD}$, highlighting some of the current issues and new developments in DBS.

\section{Overview of medical management of PD}

The basic approach to PD management begins with the identification of specific symptoms that contribute significantly to disability and also are amenable to therapy. Typically, the cardinal motor symptoms are most responsive to classic
PD pharmacotherapy. Great care must be exercised by patients and clinicians to avoid targeting symptoms that are unrelated to PD with PD medications, as well as not to mislead patients by attributing symptoms to PD when they are due to other causes. If the initial target symptoms are of sufficient severity to affect daily activities, anti-PD therapy is generally recommended. Levodopa and its many formulations, synthetic dopamine agonists, inhibitors of monoamine oxidase-type $\mathrm{B}$, anticholinergics, and amantadine can all be used as first-line medications, either alone or in combinations. Inhibitors of catechol- $O$-methyltransferase are not utilized as monotherapy, but can augment the effect of levodopa formulations as well.

As disease duration lengthens, patients usually require multiple adjustments to their medication regimens. Generally, motor fluctuations begin to occur, and often, these can be treated by shortening the interval between medication doses or by the use of longer acting formulations. Although longer acting medications may offer greater convenience in administration, often, motor fluctuations are better treated with more frequent dosing of shorter acting medications due to problems with absorption of longer acting formulations or due to side effects. For example, synthetic dopamine agonists are generally longer acting than levodopa, but can lead to complications such as impulsivity and sleepiness. Longer acting forms of levodopa are also currently more expensive.

Dyskinesias occur in a majority of medicated PD patients over time, with estimates of $40 \%-50 \%$ of PD patients developing dyskinesias within 4-6 years. ${ }^{5,24}$ Onset of dyskinesias is most commonly correlated with duration and dose of levodopa as well as disease duration itself. ${ }^{24}$ A common misconception is that dyskinesias always indicate overdosing of anti-PD medications. In fact, many times, the optimal medication regimen with the least disability and fewest side effects is marked by prominent dyskinesias.

Optimal medical management of PD is not just limited to treatment of cardinal motor symptoms. A myriad of symptoms, collectively termed "nonmotor" symptoms, may occur in association with these classic PD symptoms and include orthostatic hypotension, constipation, urinary changes, depression, psychosis, sleep disorders, and cognitive dysfunction, among others. ${ }^{6,7}$ Some of these symptoms can be directly impacted by anti-PD medications, and medications used specifically to target nonmotor symptoms can also affect motor symptoms of PD. ${ }^{8}$ A comprehensive review of non-motor symptoms is beyond the scope of this article; however, a few basic principles are noteworthy.

Since dopamine affects multiple body functions outside the motor system, administering dopaminergic medications 
to patients will undoubtedly affect these other systems. For example, dopamine acts as a vasodilator and lowers blood pressure by its peripheral receptors. This effect varies substantially from person to person, and management is variable as well. Ensuring adequate dosing of a peripheral dopa decarboxylase inhibitor such as carbidopa should be the first step in mitigating this effect. Administration of oral water is another important intervention. Plain water lowers the portal vein osmolality and is preferred to other liquids and even intravenous fluids. ${ }^{25,26}$ Occasionally, $\alpha$-adrenergic receptor agonists such as midodrine or mineralocorticoids such as fludrocortisone are needed. Droxidopa, a synthetic amino acid and precursor of norepinephrine, has also been FDA approved to treat neurogenic orthostatic hypotension. ${ }^{27,28}$

Another potentially dose-limiting effect from PD medications can be exacerbation of impulsivity. Although drawing a sharp line between normal behavior and pathologic impulsivity can be diagnostically challenging, cases of patients gambling away life savings and marital discord from hypersexuality have been encountered. Synthetic dopamine agonist use has been closely tied to impulse control disorders, and reducing the dose or eliminating them entirely often results in resolution of these problems. ${ }^{29,30}$ Geographic region (USA), younger age of onset, being unmarried, current cigarette smoking, and a family history of gambling problems have also been identified as risk factors for impulse control disorders in an international study published in 2009. ${ }^{30}$

Other neuropsychiatric problems including dementia and psychosis also complicate the management of many patients with advanced PD. Rivastigmine remains the only FDA-approved medication for dementia in PD, and pimavanserin was recently FDA approved as the first medication specifically for PD psychosis. ${ }^{31,32}$ However, quetiapine and clozapine can both be effective antipsychotic medications in PD patients as well. ${ }^{33,34}$

Even medical conditions not associated with PD can be affected by $\mathrm{PD}$, and patients and clinicians need to be mindful of these effects. For example, monoamine oxidase-B inhibitors can interact with decongestants and antidepressant medications. Amantadine and dopamine agonists may cause peripheral edema. Antiemetics that block dopamine, such as metoclopramide, can also worsen PD and even precipitate parkinson hyperpyrexia syndrome, a potentially fatal condition. ${ }^{35}$

\section{Utility of DBS in PD}

The modern evolution of DBS therapy began in the late 1980s with Dr Benabid's experimental use of continuous highfrequency stimulation in the thalamus for PD tremor. ${ }^{36}$
However, prior to that, surgical therapy for movement disorders can be traced back as far as the early 1900s. Surgical therapy for PD started in earnest with analysis of PD patients who improved following stroke, which eventually led to identification of nuclei in the anterior thalamus that could be targeted therapeutically. ${ }^{37-41}$ After the creation of the stereotactic head frame in the 1940s and magnetic resonance imaging techniques in the 1980 s, this led to the advent of various surgical lesioning techniques focusing on specific symptoms with varying levels of efficacy. ${ }^{41}$ Targeting of nuclei connecting to the ventral thalamus, namely, the internal pallidum and subthalamic nucleus (STN), also appeared to be beneficial in PD and furthered the field. ${ }^{41-44}$ However, major confounding problems with lesioning surgeries still include lack of predictability of initial outcome, lack of precision in identifying the correct target, the inability to easily modify postsurgical outcomes, and a waning of efficacy over time. ${ }^{41}$

DBS became a strong alternative to initial lesioning techniques due to its relatively small permanent lesional effect and the modifiable postsurgical outcomes, given the ability to program and adjust the implanted neurosurgical apparatus. ${ }^{45}$ It received US FDA approval for the treatment of PD in 2002.

DBS applies intermittent direct electrical current to the selected target with frequencies above the native firing rates in these areas. ${ }^{46}$ It was initially proposed that stimulation blocked depolarization of neurons within close proximity to the electrode. However, effects on neurotransmitters from the neurons not in close proximity suggested other mechanisms of action, such as effects on neurotransmitter release. ${ }^{46-48}$ The overall net clinical effect of DBS appears to be largely an inhibitory effect, though not equivalent to a standard ablation-type lesion. ${ }^{46-48}$ Entrainment of local neurons has been demonstrated during intraoperative stimulation of neurons in globus pallidus interna (GPi), and alterations in neuron firing have also been demonstrated during intraoperative stimulation of STN. ${ }^{49,50}$

There is a large body of literature demonstrating the benefit of DBS in PD. Compared to best medical therapy alone, DBS in conjunction with medication is far superior in controlling levodopa-responsive motor symptoms. ${ }^{9-14}$ DBS is also approved for tremor and can have added benefit in treating medication-refractory PD tremor. Specifically, various studies have demonstrated an overall improvement in quality of life, motor scores, dyskinesias, and reduction of wearing off in patients who have received DBS. ${ }^{13,14,51}$ DBS benefits have also been maintained for $>10$ years in recently documented long-term follow-up studies. ${ }^{52-54}$ The STN and 
GPi are currently the preferred targets, but the ventral intermediate thalamus (VIM) can also be utilized when tremor is the primary symptom. ${ }^{55-57}$ On an experimental basis, the pedunculopontine nucleus (PPN) has also been explored in patients with axial symptoms and difficulties with freezing of gait with varying success. ${ }^{58-63}$

DBS is overall considered a relatively safe neurosurgical procedure with low mortality. However, akin to other surgical procedures, DBS surgeries can be complicated by intraoperative and immediate postoperative deterioration. Among others, major concerns would include intracranial bleeding, seizure, stroke, hardware malfunction, infection, prolonged length of hospitalization, and postoperative confusion. The rate of postoperative complications is related both to the length of postoperative follow-up and the intensity of invest igation. ${ }^{9,14,19,20,55,64-66}$ In a recent representative study by Chen et al, the rate of cerebral hemorrhage was $1.4 \%$ and the rate of hardware infection was $1.1 \%$. Postoperative mental status change occurred in $4.6 \%$, and seizure occurred in $1.4 \%{ }^{64}$ In contrast, a study by Doshi in 2011 with a longer mean duration of follow-up showed confusion in $3.9 \%$, hardware infection in $4.5 \%$, and malfunction of the implantable pulse generator (IPG) in $1.4 \% .{ }^{65}$ These studies nicely illustrate that complication numbers can vary considerably from study to study depending on several variables including the DBS center, surgeon experience, definition of a complication (ie, different centers investigate and diagnose postoperative infection differently), and surgical techniques.

"Dose-limiting" side effects of stimulation can also occur, often resulting from excess current delivery to the target area and adjacent tissue. Paresthesias, diplopia, and muscle contraction can all occur acutely or in a delayed fashion. ${ }^{67}$ Effects on cognition, speech, and mood have also been observed with chronic stimulation. ${ }^{21,22,68}$ It is not fully clear to what extent these conditions are due to underlying disease progression or to actual stimulation effects.

Many other side effects of DBS are not directly related to stimulation intensity, but occur related to the surgical manipulation itself or to failure of the hardware. Hardware failure can occur as a result of blunt force trauma or the electromagnetic pulses from medical devices such as magnetic resonance imaging and defibrillators. ${ }^{69}$ In addition, the sensation of tethering occurs commonly. ${ }^{70,71}$ Tethering occurs when the extension wire connecting the brain wire to the IPG forcibly contacts the neighboring tissue in the neck during head turning, flexion, or extension..$^{70,71}$ This problem can vary considerably in severity from patient to patient and from movement to movement.
Finally, there are suboptimal outcomes that occur after PD DBS as well as for its other indications that cannot be blamed on the more common issues such as hardware complications, surgical complications, poor electrode positioning, or problems with programming. ${ }^{72,73}$ In $\mathrm{PD}$, this can manifest as reemergence of dystonia, worsening in motor fluctuations and dyskinesias, and progression of the cardinal motor symptoms initially modified by DBS. ${ }^{73}$ Varying techniques, often employing more surgical measures, have been used to try and rescue "failed" DBS implants. ${ }^{73}$

\section{DBS programming}

Once the lead is effectively placed, programming must be optimized to maximize clinical outcome. There is no single algorithm for DBS programming or reprogramming in movement disorders such as PD, but changing contact configuration and adjusting amplitude and pulse width are the most common parameters adjusted. ${ }^{67,74}$ Most providers start by interrogating the system before proceeding with actual programming. Lead fractures or other damage to the system will generally manifest as an abnormal impedance in one or more contacts. Intact contacts can then be tested sequentially or in combination to establish the efficacy and side effect thresholds and ranges. ${ }^{67,74}$ Once the optimal balance of efficacy and side effects is determined, additional programming may attempt to lower the current delivery or to reduce transient side effects that can occur when the device is switched on or when settings are changed. In some patients, there may be more than one optimal setting. For some patients, multiple groups can be programmed, allowing the patient to switch from one to another outside the hospital or clinic setting. Some patients may find that one setting has better motor control but worse dysarthria, while another setting sacrifices some motor control and allows better verbal communication. ${ }^{67,74}$

More varied patterns of DBS signal delivery are also being explored, such as with more varied nonrectangular wave forms, biphasic pulses, and other novel techniques. ${ }^{75}$ We will highlight the novel use of low-frequency stimulation here given frequency can presently be easily adjusted but is rarely a parameter that is modified during typical DBS programming. DBS programming traditionally utilizes high-frequency stimulation, often considered as $>100 \mathrm{~Hz} .{ }^{76}$ Stimulation frequency generally exceeds the typical firing rate of a neuron in order to block repolarization and subsequent depolarization. In theory, adjusting the frequency in DBS could be akin to changing the threshold for neurons to discharge, altering the relative population of neurons sending out action potentials. 
Early studies of low-frequency stimulation in PD have examined whether certain symptoms that appeared to worsen with higher frequency stimulation could be improved with lowering the frequency. Often, gait or dysarthria was examined, as these symptoms are often unaffected or even worsened by DBS in PD, particularly in the ON medication state. Moreau et al examined 13 PD patients with two different frequencies $(60$ and $130 \mathrm{~Hz})$ and found that the $60 \mathrm{~Hz}$ frequency substantially reduced freezing of gait episodes. ${ }^{77}$ Subsequent studies have had difficulty replicating these results, often finding worsening motor symptoms as well as a lack of benefit in gait with lower frequencies. ${ }^{78,79}$ A recent retrospective study by Zibetti et al showed 64\% of patients had subjective improvement of axial symptoms when switched from higher to lower frequency stimulation with increased voltage.$^{80}$ Because changing the stimulation frequency may change the impedance, studies of frequency need to adjust other parameters in order to maintain neutral current delivery. These adjustments may affect the given symptoms differently; thus, interpretation of the pure effect of frequencies may not be possible.

In these studies, other variables that may affect DBS effects outside of the electrical adjustments include surgical technique, timing of the outcome assessments, PD medication dose quantity, and many other individual patient characteristics. In addition, some programmers may test multiple frequencies during routine programming, while others may wait until side effects develop, creating a selection bias with only certain patients being exposed to lower (or higher) frequencies. Thus, although a given patient may benefit from a change in frequency during DBS reprogramming, it is likely that there is not one single best frequency for all patients. It is also possible that the optimal frequency for the same patient may change over the course of DBS therapy.

\section{Target selection}

As mentioned, there are two main anatomic targets for PD the STN and the GPi. There have been several large randomized studies comparing STN and GPi DBS in PD which suggest that both targets are overall equally effective for motor symptom control and similar in cost-effectiveness. ${ }^{55,81-86}$ Various post hoc and nonrandomized studies building on these large randomized comparative trials have suggested some differential effects on dyskinesias, medication requirements, verbal fluency impact, gait changes, and other parameters. ${ }^{55,82,87}$ Due to significant differences in the treatment paradigms and often a lack of randomization, these studies do not allow for direct comparisons, making definitive conclusions difficult. Many DBS centers still will preferentially use the target for which they have greater experience. Nonetheless, it is becoming more accepted that the GPi is more favorable for those with more axial symptoms, gait issues, depression, and word fluency problems. ${ }^{87}$ Many centers also favor the GPi when dyskinesias are especially problematic. In turn, the STN is often favored in those with higher medication requirements, given a higher published ability to decrease medication postsurgery and, for some centers, in those with greater tremor. ${ }^{87}$ Continuing to define target differences in order to better individualize the DBS experience is a considerable area of interest for DBS physicians. One could also speculate that, in some patients with differing symptoms on either side, choosing a different target for each side of the brain could be better than symmetrical, bilateral targeting, though this technique has not been extensively studied.

In addition to the current main targets, the VIM is still used for severe medication-refractory PD tremor with success. ${ }^{56,57}$ Unfortunately, the VIM target does not effectively address other parkinsonian motor symptoms outside of tremor. Most intriguing, the PPN region, often designated as the PPNa (area), has also been explored for more axial symptoms, namely problems with gait, which are often unimproved by stimulation from the main STN and GPi targets. In some cases, particularly with the STN target, these symptoms may worsen. ${ }^{88}$ Results from stimulation of this target have been inconsistent. A recent meta-analysis by Wang et al looking at DBS targeting of the PPNa suggests that this therapy can be effective in improving gait. ${ }^{59}$ Interestingly, many of the reported cases also underwent bilateral STN stimulation, and frequencies for PPNa stimulation were often in the low-frequency range $(<100 \mathrm{~Hz}){ }^{59,89}$ Other reviews of PPNa studies were not as promising (see the meta-analysis by Golestanirad et $\mathrm{a}^{162}$ and the review by Snijders et $\mathrm{a}^{58}$ ). There are a number of issues that still need to be addressed before this target is used outside the research setting, but a crucial issue remains identification of the best target within the PPNa. ${ }^{61}$

\section{New technology (new lead technology and "closed-loop" DBS)}

Although DBS has been proven to provide superior benefits over medicinal therapy alone, DBS programmers are still limited in maximizing outcome by positioning of the electrode in surgery (either good or bad) and due to the inability of the current programming parameters to adjust and respond depending on feedback from the outside environment. 
Current developing new technologies include 1) newer leads with the capability to "direct current" preferentially in a nonconcentric pattern; 2) the capability to sense from the electrode and then alter the output from the IPG based upon that input - a so-called "closed-loop" system.

The capability to direct current offers many potential benefits, allowing clinicians the ability to drive stimulation away from neighboring areas that are causing stimulationlimiting side effects, particularly when the electrodes are not ideally placed. Presently, clinicians have the ability to change active contact configurations from simple monopolar settings to bipolar and to employ interleaving, a technique that allows two different programs to run alternatively. Impending new DBS lead technology will allow some degree of "current steering" or the ability to apply current in other than a concentric ring around the activated contact(s) as is the case with the current four-contact lead. ${ }^{75,90}$ Most future DBS electrodes also will have more than four contacts, allowing for finer control of the stimulated areas. One exciting new pending electrode will have some segmented contacts, with each piece having the potential to be individually stimulated. St Jude has had approval for this technology in Europe and was recently granted FDA approval in the USA for PD and essential tremor indications. In a small study by Pollo et al ( $\mathrm{N}=13)$, blinded intraoperative use of directional current with these segmented electrodes demonstrated a higher therapeutic window $(>41.3 \%)$ in PD targeting STN and in essential tremor targeting the thalamus, compared to normal omnidirectional stimulation. ${ }^{91}$ Because this study was performed only intraoperatively, there was no evaluation to determine whether this difference could be maintained long term. Other impending leads produced by Boston Scientific with eight contacts have the potential for independent current sources allowing for separate manipulation of the typical DBS parameters (amplitude, frequency, pulse width, and current) at each contact. ${ }^{75,90}$ This technology has already been approved for use in Europe. Timmermann et al published a recent large open-label, nonrandomized, prospective study looking at $53 \mathrm{PD}$ patients bilaterally implanted with this lead technology and found it to be safe and efficacious. ${ }^{92}$ Steigerwald et al examined seven PD patients 4-9 days after bilateral implantation with the Boston Scientific lead, comparing programming of standard monopolar settings versus more complex settings using the current shaping capabilities of the new technology in a nonblinded fashion. ${ }^{93}$ They found that the directional current capabilities of the new technology could be more beneficial, especially at less beneficial contacts in the simple monopolar settings. ${ }^{93}$ To what extent this technology benefits patients is still unclear at this time, given the limited published research and essential absence of comparative trials. However, the potential to shield some brain regions with current shaping and steering may be useful to lower the side effects. Potential negatives to this exciting technology include increased programming time with further programming alternatives, the degree of the programmer's accuracy in "steering" the electrical current to the needed areas, and the fact that the decreased surface area due to the smaller size of the contacts will inevitably increase impedances, potentially leading to greater consumption of battery power. ${ }^{75,90}$

Another interesting method of steering current has been used already at our center. In patients with essential tremor poorly responsive to initial DBS, another set of electrodes was placed in close proximity so that current could be directed from one electrode to the other as demonstrated in a study by Yu et al. ${ }^{94}$ This paradigm has been employed as a "rescue" therapy for essential tremor patients with benefit. ${ }^{73}$ Comparisons between single-electrode shielded current versus electrode-to-electrode cross current delivery have not been done. However, speculation would suggest that a two-electrode system would provide greater volume of tissue activation, but might also cause relatively more static damage by virtue of the second electrode lesioning more frontal lobe circuitry.

Another exciting piece of technology in development is closed-loop DBS. Current DBS systems are programmed to emit pulses of electrical current in fairly simple, repetitive patterns using preprogrammed parameters in a so-called open-loop system. These settings remain unchanged and independent of any outside variables or feedback. However, in a similar fashion to the way modern cardiac pacemakers can change output patterns depending upon input from sensors of heart rhythm, DBS devices are being developed that can utilize input from brain activity through a so-called closed-loop system. ${ }^{95,96}$ This emerging technology is still early in the development cycle, but potential applications are multifold. ${ }^{75,90,97}$ A major limitation, however, is still determining what the brain activity or "input signal" is to trigger the appropriate change in the DBS system. ${ }^{75}$ For PD, current basal ganglia electrical activity and fluctuation of neighboring neurons primarily in the beta band range $(13-30 \mathrm{~Hz})$ are actively being studied as the indicator of uncontrolled PD symptomatology and changing clinical state. ${ }^{75,98}$ There are some limited studies looking at frequencies in the gamma range as well, primarily in regard to controlling PD tremor and dyskinesias. ${ }^{75,99,100}$ 
With further development of this technology, needed programming adjustments could be lessened, battery life prolonged, DBS side effects further minimized, and motor symptoms better controlled in real time. Potential uses of this new technology could include prolonging battery life by reducing output during sleep and less needed times as well as delivering different output during times when things like freezing occur to "unfreeze" the patient. Also, bothersome motor features and dyskinesias could be more effectively managed in relation to PD medication dosing times. ${ }^{75,90,97}$

\section{Conclusion}

In summary, DBS has been shown to be a safe and effective therapy for PD and its other indications. The best PD patients for DBS are patients with clear, substantial levodopa responsiveness, having relatively few comorbidities (especially the absence of cognitive difficulties), and with clear therapeutic goals for surgery that are already modified by their medications (exception of medication-resistant tremor). The mantra "best ON more often" aptly describes DBS physicians' hopes for a successful DBS surgery. As detailed in this review, the most concerning current difficulties with DBS include continued occasional surgical complications, hardware failure, and worsening of neuropsychiatric status. Standard protocols to reduce these risks as much as possible are still in need of development. Further, the reasons behind the occasional suboptimal DBS responder, irrespective of the aforementioned more common surgical complications, as well as the most appropriate next steps in management need to be better explored. Prominent issues still being explored include better tailoring of anatomic targets to individual patients and adjusting DBS signal delivery such as with low-frequency stimulation. Finally, there are several exciting emerging technological advances that may further improve DBS outcomes, such as directional current delivery through new lead technology and closed-loop DBS.

\section{Author contributions}

All authors made substantial contributions to conception and design, drafting of the article and revising it critically for important intellectual content, gave final approval of the version to be published, and agree to be accountable for all aspects of the work in ensuring that questions related to the accuracy or integrity of any part of the work are appropriately investigated and resolved.

\section{Disclosure}

Dr Tolleson has done consulting work for Medtronic, Acadia, and Teva. Dr Fang receives grant support from an ongoing clinical trial (SURE-PD3, funded by NINDS/NIH under Award Number 1U01NS090259-01A1, National Center for Advancing Translational Sciences of the National Institute of Health under Award Number UL1 TR000445, and the Michael J Fox Foundation). The mentioned entities had no role in the topics of the invited review; in the writing of the manuscript, and in the decision to publish.

\section{References}

1. Parkinson J. An essay on the shaking palsy. 1817. J Neuropsychiatry Clin Neurosci. 2002;14(2):223-236.

2. Hughes AJ, Daniel SE, Kilford L, Lees AJ. Accuracy of clinical diagnosis of idiopathic Parkinson's disease: a clinico-pathological study of 100 cases. J Neurol Neurosurg Psychiatry. 1992;55(3):181-184.

3. Postuma RB, Berg D, Adler CH, et al. The new definition and diagnostic criteria of Parkinson's disease. Lancet Neurol. 2016;15(6):546-548.

4. Cotzias GC, Van Woert MH, Schiffer LM. Aromatic amino acids and modification of parkinsonism. N Engl J Med. 1967;276(7):374-379.

5. Bjornestad A, Forsaa EB, Pedersen KF, Tysnes OB, Larsen JP, Alves G. Risk and course of motor complications in a population-based incident Parkinson's disease cohort. Parkinsonism Relat Disord. 2016;22:48-53.

6. Witjas T, Kaphan E, Azulay JP, et al. Nonmotor fluctuations in Parkinson's disease: frequent and disabling. Neurology. 2002;59(3):408-413.

7. Zesiewicz TA, Sullivan KL, Arnulf I, et al. Practice parameter: treatment of nonmotor symptoms of Parkinson disease: report of the quality standards subcommittee of the American academy of neurology. Neurology. 2010;74(11):924-931.

8. Martinez-Fernandez R, Schmitt E, Martinez-Martin P, Krack P. The hidden sister of motor fluctuations in Parkinson's disease: a review on nonmotor fluctuations. Mov Disord. 2016;31(8):1080-1094.

9. Deuschl G, Schade-Brittinger C, Krack P, et al. A randomized trial of deep-brain stimulation for Parkinson's disease. $N$ Engl J Med. 2006; 355(9):896-908.

10. Kleiner-Fisman G, Herzog J, Fisman DN, et al. Subthalamic nucleus deep brain stimulation: summary and meta-analysis of outcomes. Mov Disord. 2006;21(Suppl 1):S290-S304.

11. Schupbach WMM, Maltete D, Houeto JL, et al. Neurosurgery at an earlier stage of Parkinson disease: a randomized, controlled trial. Neurology. 2007;68(4):267-271.

12. Volkmann J, Allert N, Voges J, Sturm V, Schnitzler A, Freund HJ. Long-term results of bilateral pallidal stimulation in Parkinson's disease. Ann Neurol. 2004;55(6):871-875.

13. Williams A, Gill S, Varma T, et al. Deep brain stimulation plus best medical therapy versus best medical therapy alone for advanced Parkinson's disease (PD SURG trial): a randomised, open-label trial. Lancet Neurol. 2010;9(6):581-591.

14. Weaver FM, Follett K, Stern M, et al. Bilateral deep brain stimulation vs best medical therapy for patients with advanced Parkinson disease: a randomized controlled trial. JAMA. 2009;301(1):63-73.

15. Merola A, Espay AJ, Romagnolo A, et al. Advanced therapies in Parkinson's disease: long-term retrospective study. Parkinsonism Relat Disord. 2016;29:104-108.

16. Palhagen SE, Sydow O, Johansson A, et al. Levodopa-carbidopa intestinal gel (LCIG) treatment in routine care of patients with advanced Parkinson's disease: an open-label prospective observational study of effectiveness, tolerability and healthcare costs. Parkinsonism Relat Disord. 2016;29:17-23.

17. Zibetti M, Merola A, Artusi CA, et al. Levodopa/carbidopa intestinal gel infusion in advanced Parkinson's disease: a 7-year experience. Eur J Neurol. 2014;21(2):312-318.

18. Garcia Ruiz PJ, Sesar Ignacio A, Ares Pensado B, et al. Efficacy of long-term continuous subcutaneous apomorphine infusion in advanced Parkinson's disease with motor fluctuations: a multicenter study. Mov Disord. 2008;23(8):1130-1136. 
19. Bronstein JM, Tagliati M, Alterman RL, et al. Deep brain stimulation for Parkinson disease: an expert consensus and review of key issues. Arch Neurol. 2011;68(2):165.

20. Hamani C, Lozano AM. Hardware-related complications of deep brain stimulation: a review of the published literature. Stereotact Funct Neurosurg. 2006;84(5-6):248-251.

21. Okun MS, Fernandez HH, Wu SS, et al. Cognition and mood in Parkinson's disease in subthalamic nucleus versus globus pallidus interna deep brain stimulation: the COMPARE trial. Ann Neurol. 2009; 65(5):586-595.

22. Saint-Cyr JA, Trepanier LL, Kumar R, Lozano AM, Lang AE. Neuropsychological consequences of chronic bilateral stimulation of the subthalamic nucleus in Parkinson's disease. Brain. 2000;123 (Pt 1): 2091-2108.

23. Tolleson C, Stroh J, Ehrenfeld J, Neimat J, Konrad P, Phibbs F. The factors involved in deep brain stimulation infection: a large case series. Stereotact Funct Neurosurg. 2014;92(4):227-233.

24. Scott NW, Macleod AD, Counsell CE. Motor complications in an incident Parkinson's disease cohort. Eur J Neurol. 2016;23(2):304-312.

25. Jordan J, Shannon JR, Black BK, et al. The pressor response to water drinking in humans: a sympathetic reflex? Circulation. 2000;101(5): 504-509.

26. Schroeder C, Bush VE, Norcliffe LJ, et al. Water drinking acutely improves orthostatic tolerance in healthy subjects. Circulation. 2002; 106(22):2806-2811.

27. Kaufmann H, Freeman R, Biaggioni I, et al. Droxidopa for neurogenic orthostatic hypotension: a randomized, placebo-controlled, phase 3 trial. Neurology. 2014;83(4):328-335.

28. Hauser RA, Isaacson S, Lisk JP, Hewitt LA, Rowse G. Droxidopa for the short-term treatment of symptomatic neurogenic orthostatic hypotension in Parkinson's disease (nOH306B). Mov Disord. 2015;30(5): 646-654.

29. Ceravolo R, Frosini D, Rossi C, Bonuccelli U. Impulse control disorders in Parkinson's disease: definition, epidemiology, risk factors, neurobiology and management. Parkinsonism Relat Disord. 2009;15(Suppl 4): S111-S115.

30. Weintraub D. Impulse control disorders in Parkinson's disease: prevalence and possible risk factors. Parkinsonism Relat Disord. 2009; 15(Suppl 3):S110-S113.

31. Emre M, Aarsland D, Albanese A, et al. Rivastigmine for dementia associated with Parkinson's disease. $N$ Engl J Med. 2004;351(24): 2509-2518

32. Cummings J, Isaacson S, Mills R, et al. Pimavanserin for patients with Parkinson's disease psychosis: a randomised, placebo-controlled phase 3 trial. Lancet. 2014;383(9916):533-540.

33. Emre M, Ford PJ, Bilgic B, Uc EY. Cognitive impairment and dementia in Parkinson's disease: practical issues and management. Mov Disord. 2014;29(5):663-672.

34. Rabey JM. Hallucinations and psychosis in Parkinson's disease. Parkinsonism Relat Disord. 2009;15(Suppl 4):S105-S10.

35. Granner MA, Wooten GF. Neuroleptic malignant syndrome or parkinsonism hyperpyrexia syndrome. Semin Neurol. 1991;11(3):228-235.

36. Benabid AL, Pollak P, Louveau A, Henry S, de Rougemont J. Combined (thalamotomy and stimulation) stereotactic surgery of the VIM thalamic nucleus for bilateral Parkinson disease. Appl Neurophysiol. 1987;50(1-6):344-346.

37. Hassler R. The influence of stimulations and coagulations in the human thalamus on the tremor at rest and its physiopathologic mechanism. In: Proceedings of the Second International Congress on Neuropathology. Amsterdam: Excerpta Medica Foundation; 1955:637-642.

38. Hassler R. The pathological and pathophysiological basis of tremor and parkinsonism. In: Proceedings of the Second International Congress on Neuropathology. Amsterdam: Excerpta Medica Foundation; 1955: 29-40.

39. COOPER IS. Surgical alleviation of Parkinsonism; effects of occlusion of the anterior choroidal artery. J Am Geriatr Soc. 1954;2(11): 691-718.
40. COOPER IS. Ligation of the anterior choroidal artery for involuntary movements; parkinsonism. Psychiatr Q. 1953;27(2):317-319.

41. Okun MS, Vitek JL. Lesion therapy for Parkinson's disease and other movement disorders: update and controversies. Mov Disord. 2004; 19(4):375-389.

42. Alvarez L, Macias R, Lopez G, et al. Bilateral subthalamotomy in Parkinson's disease: initial and long-term response. Brain. 2005;128(Pt3): 570-583.

43. Laitinen LV, Bergenheim AT, Hariz MI. Leksell's posteroventral pallidotomy in the treatment of Parkinson's disease. J Neurosurg. 1992; 76(1):53-61.

44. Fine J, Duff J, Chen R, et al. Long-term follow-up of unilateral pallidotomy in advanced Parkinson's disease. $N$ Engl J Med. 2000; 342(23):1708-1714.

45. Volkmann J. Surgery for Parkinson's disease. In: Hallet M, Poewe W, editors. Therapeutics of Parkinson's Disease and Other Movement Disorders. Chichester, West Sussex, UK: John Wiley and Sons Ltd; 2008 : 121-136.

46. Benazzouz A, Hallett M. Mechanism of action of deep brain stimulation. Neurology. 2000;55(12 Suppl 6):S13-S16.

47. Okun MS, Oyama G. Mechanism of action for deep brain stimulation and electrical neuro-network modulation (ENM). Rinsho Shinkeigaku. 2013;53(9):691-694. Japanese.

48. Hammond C, Ammari R, Bioulac B, Garcia L. Latest view on the mechanism of action of deep brain stimulation. Mov Disord. 2008;23(15): 2111-2121.

49. Cleary DR, Raslan AM, Rubin JE, et al. Deep brain stimulation entrains local neuronal firing in human globus pallidus internus. J Neurophysiol. 2013;109(4):978-987.

50. Carlson JD, Cleary DR, Cetas JS, Heinricher MM, Burchiel KJ. Deep brain stimulation does not silence neurons in subthalamic nucleus in Parkinson's patients. J Neurophysiol. 2010;103(2):962-967.

51. Sharma A, Szeto K, Desilets AR. Efficacy and safety of deep brain stimulation as an adjunct to pharmacotherapy for the treatment of Parkinson disease. Ann Pharmacother. 2012;46(2):248-254.

52. Zibetti M, Merola A, Rizzi L, et al. Beyond nine years of continuous subthalamic nucleus deep brain stimulation in Parkinson's disease. Mov Disord. 2011;26(13):2327-2334.

53. Rizzone MG, Fasano A, Daniele A, et al. Long-term outcome of subthalamic nucleus DBS in Parkinson's disease: from the advanced phase towards the late stage of the disease? Parkinsonism Relat Disord. 2014;20(4):376-381.

54. Castrioto A, Lozano AM, Poon YY, Lang AE, Fallis M, Moro E. Ten-year outcome of subthalamic stimulation in Parkinson disease: a blinded evaluation. Arch Neurol. 2011;68(12):1550-1556.

55. Follett KA, Weaver FM, Stern M, et al. Pallidal versus subthalamic deep-brain stimulation for Parkinson's disease. $N$ Engl J Med. 2010; 362(22):2077-2091.

56. Hariz MI, Krack P, Alesch F, et al. Multicentre European study of thalamic stimulation for parkinsonian tremor: a 6 year follow-up. J Neurol Neurosurg Psychiatry. 2008;79(6):694-699.

57. Fox SH, Katzenschlager R, Lim S-Y, et al. The movement disorder society evidence-based medicine review update: treatments for the motor symptoms of Parkinson's disease. Mov Disord. 2011;26(Suppl 3): $\mathrm{S} 2-\mathrm{S} 41$.

58. Snijders AH, Takakusaki K, Debu B, et al. Physiology of freezing of gait. Ann Neurol. 2016;80(5):644-659.

59. Wang H, Gao H, Jiao T, Luo Z. A meta-analysis of the pedunculopontine nucleus deep-brain stimulation effects on Parkinson's disease. Neuroreport. 2016;27(18):1336-1344.

60. Mazzone P, Scarnati E, Garcia-Rill E. Commentary: the pedunculopontine nucleus: clinical experience, basic questions and future directions. J Neural Transm. 2011;118(10):1391-1396.

61. Hamani C, Lozano AM, Mazzone PAM, et al. Pedunculopontine nucleus region deep brain stimulation in Parkinson disease: surgical techniques, side effects, and postoperative imaging. Stereotact Funct Neurosurg. 2016;94(5):307-319. 
62. Golestanirad L, Elahi B, Graham SJ, Das S, Wald LL. Efficacy and safety of pedunculopontine nuclei (PPN) deep brain stimulation in the treatment of gait disorders: a meta-analysis of clinical studies. Can J Neurol Sci. 2016;43(1):120-126.

63. Ferraye MU, Debu B, Fraix V, et al. Effects of pedunculopontine nucleus area stimulation on gait disorders in Parkinson's disease. Brain. 2010;133(Pt 1):205-214.

64. Chen T, Mirzadeh Z, Chapple K, Lambert M, Ponce FA. Complication rates, lengths of stay, and readmission rates in "awake" and "asleep" deep brain simulation. J Neurosurg. In press 2016.

65. Doshi PK. Long-term surgical and hardware-related complications of deep brain stimulation. Stereotact Funct Neurosurg. 2011;89(2): 89-95.

66. Voges J, Hilker R, Botzel K, et al. Thirty days complication rate following surgery performed for deep-brain-stimulation. Mov Disord. 2007; 22(10):1486-1489.

67. Deuschl G, Herzog J, Kleiner-Fisman G, et al. Deep brain stimulation: postoperative issues. Mov Disord. 2006;21(Suppl 1):S219-S237.

68. Krack P, Fraix V, Mendes A, Benabid AL, Pollak P. Postoperative management of subthalamic nucleus stimulation for Parkinson's disease. Mov Disord. 2002;17(Suppl 3):S188-S197.

69. Blomstedt P, Jabre M, Bejjani BP, Koskinen LO. Electromagnetic environmental influences on implanted deep brain stimulators. Neuromodulation. 2006;9(4):262-269.

70. Miller PM, Gross RE. Wire tethering or "bowstringing" as a long-term hardware-related complication of deep brain stimulation. Stereotact Funct Neurosurg. 2009;87(6):353-359.

71. Janson C, Maxwell R, Gupte AA, Abosch A. Bowstringing as a complication of deep brain stimulation: case report. Neurosurgery. 2010; 66(6):E1205.

72. Oyama G, Foote KD, Hwynn N, et al. Rescue leads: a salvage technique for selected patients with a suboptimal response to standard DBS therapy. Parkinsonism Relat Disord. 2011;17(6):451-455.

73. Nagy AM, Tolleson CM. Rescue Procedures after Suboptimal Deep Brain Stimulation Outcomes in Common Movement Disorders. Brain Sci. 2016;6(4):E46.

74. Volkmann J, Moro E, Pahwa R. Basic algorithms for the programming of deep brain stimulation in Parkinson's disease. Mov Disord. 2006; 21(Suppl 1):S284-S289.

75. Deeb W, Giordano JJ, Rossi PJ, et al. Proceedings of the fourth annual deep brain stimulation think tank: a review of emerging issues and technologies. Front Integr Neurosci. 2016;10:38.

76. di Biase L, Fasano A. Low-frequency deep brain stimulation for Parkinson's disease: great expectation or false hope? Mov Disord. 2016;31(7):962-967.

77. Moreau C, Defebvre L, Destee A, et al. STN-DBS frequency effects on freezing of gait in advanced Parkinson disease. Neurology. 2008; 71(2):80-84.

78. Phibbs FT, Arbogast PG, Davis TL. 60-Hz frequency effect on gait in Parkinson's disease with subthalamic nucleus deep brain stimulation. Neuromodulation. 2014;17(8):717-720.

79. Timmermann L, Wojtecki L, Gross J, et al. Ten-Hertz stimulation of subthalamic nucleus deteriorates motor symptoms in Parkinson's disease. Mov Disord. 2004;19(11):1328-1333.

80. Zibetti M, Moro E, Krishna V, et al. Low-frequency subthalamic stimulation in Parkinson's disease: long-term outcome and predictors. Brain Stimul. 2016;9(5):774-779.

81. Anderson VC, Burchiel KJ, Hogarth P, Favre J, Hammerstad JP. Pallidal vs subthalamic nucleus deep brain stimulation in Parkinson disease. Arch Neurol. 2005;62(4):554-560.
82. Liu Y, Li W, Tan C, et al. Meta-analysis comparing deep brain stimulation of the globus pallidus and subthalamic nucleus to treat advanced Parkinson disease. J Neurosurg. 2014;121(3):709-718.

83. Moro E, Lozano AM, Pollak P, et al. Long-term results of a multicenter study on subthalamic and pallidal stimulation in Parkinson's disease. Mov Disord. 2010;25(5):578-586.

84. Odekerken VJJ, van Laar T, Staal MJ, et al. Subthalamic nucleus versus globus pallidus bilateral deep brain stimulation for advanced Parkinson's disease (NSTAPS study): a randomised controlled trial. Lancet Neurol. 2013;12(1):37-44.

85. Stroupe KT, Weaver FM, Cao L, et al. Cost of deep brain stimulation for the treatment of Parkinson's disease by surgical stimulation sites. Mov Disord. 2014;29(13):1666-1674.

86. Weaver FM, Follett KA, Stern M, et al. Randomized trial of deep brain stimulation for Parkinson disease: thirty-six-month outcomes. Neurology. 2012;79(1):55-65.

87. Williams NR, Foote KD, Okun MS. STN vs GPi deep brain stimulation: translating the rematch into clinical practice. Mov Disord Clin Pract. 2014;1(1):24-35.

88. Fleury V, Pollak P, Gere J, et al. Subthalamic stimulation may inhibit the beneficial effects of levodopa on akinesia and gait. Mov Disord. 2016; 31(9):1389-1397.

89. Stefani A, Lozano AM, Peppe A, et al. Bilateral deep brain stimulation of the pedunculopontine and subthalamic nuclei in severe Parkinson's disease. Brain. 2007;130(Pt 6):1596-1607.

90. Hariz M. Deep brain stimulation: new techniques. Parkinsonism Relat Disord. 2014;20(Suppl 1):S192-S196.

91. Pollo C, Kaelin-Lang A, Oertel MF, et al. Directional deep brain stimulation: an intraoperative double-blind pilot study. Brain. 2014;137(Pt 7): 2015-2026.

92. Timmermann L, Jain R, Chen L, et al. Multiple-source current steering in subthalamic nucleus deep brain stimulation for Parkinson's disease (the VANTAGE study): a non-randomised, prospective, multicentre, open-label study. Lancet Neurol. 2015;14(7):693-701.

93. Steigerwald F, Muller L, Johannes S, Matthies C, Volkmann J. Directional deep brain stimulation of the subthalamic nucleus: a pilot study using a novel neurostimulation device. Mov Disord. 2016;31(8): $1240-1243$.

94. Yu H, Hedera P, Fang J, Davis TL, Konrad PE. Confined stimulation using dual thalamic deep brain stimulation leads rescues refractory essential tremor: report of three cases. Stereotact Funct Neurosurg. 2009;87(5):309-313.

95. Sun FT, Morrell MJ. Closed-loop neurostimulation: the clinical experience. Neurotherapeutics. 2014;11(3):553-563.

96. Priori A, Foffani G, Rossi L, Marceglia S. Adaptive deep brain stimulation (aDBS) controlled by local field potential oscillations. Exp Neurol. 2013;245:77-86.

97. Verhagen ML, Pal G, Slavin K. Surgical treatment of Parkinson's disease. Curr Treat Options Neurol. 2016;18(11):49.

98. Little S, Brown P. What brain signals are suitable for feedback control of deep brain stimulation in Parkinson's disease? Ann N Y Acad Sci. 2012; 1265:9-24.

99. Brown P, Kupsch A, Magill PJ, Sharott A, Harnack D, Meissner W. Oscillatory local field potentials recorded from the subthalamic nucleus of the alert rat. Exp Neurol. 2002;177(2):581-585.

100. Beudel M, Little S, Pogosyan A, et al. Tremor reduction by deep brain stimulation is associated with gamma power suppression in Parkinson's disease. Neuromodulation. 2015;18(5):349-354. 


\section{Publish your work in this journal}

Neuropsychiatric Disease and Treatment is an international, peerreviewed journal of clinical therapeutics and pharmacology focusing on concise rapid reporting of clinical or pre-clinical studies on a range of neuropsychiatric and neurological disorders. This journal is indexed on PubMed Central, the 'PsycINFO' database and CAS,

and is the official journal of The International Neuropsychiatric Association (INA). The manuscript management system is completely online and includes a very quick and fair peer-review system, which is all easy to use. Visit http://www.dovepress.com/testimonials.php to read real quotes from published authors.

Submit your manuscript here: http://www.dovepress.com/neuropsychiatric-disease-and-treatment-journal 